\title{
Lusioersily
}

\section{Amorphous carbon interlayers for gold on elastomer stretchable conductors}

Manzoor, MU., Tuinea-Bobe, CL., McKavanagh, F., Byrne, CP., Dixon, D., Maguire, PD., \& Lemoine, P. (2011). Amorphous carbon interlayers for gold on elastomer stretchable conductors. Journal of Phys D, Applied Physics, 44(24), 245301-9pp. https://doi.org/10.1088/0022-3727/44/24/245301

Link to publication record in Ulster University Research Portal

Published in:

Journal of Phys D, Applied Physics

Publication Status:

Published (in print/issue): 22/03/2011

DOI:

10.1088/0022-3727/44/24/245301

\section{Document Version}

Publisher's PDF, also known as Version of record

\section{General rights}

Copyright for the publications made accessible via Ulster University's Research Portal is retained by the author(s) and / or other copyright owners and it is a condition of accessing these publications that users recognise and abide by the legal requirements associated with these rights.

\section{Take down policy}

The Research Portal is Ulster University's institutional repository that provides access to Ulster's research outputs. Every effort has been made to ensure that content in the Research Portal does not infringe any person's rights, or applicable UK laws. If you discover content in the Research Portal that you believe breaches copyright or violates any law, please contact pure-support@ulster.ac.uk. 
Amorphous carbon interlayers for gold on elastomer stretchable conductors

This article has been downloaded from IOPscience. Please scroll down to see the full text article.

2011 J. Phys. D: Appl. Phys. 44245301

(http://iopscience.iop.org/0022-3727/44/24/245301)

View the table of contents for this issue, or go to the journal homepage for more

Download details:

IP Address: 193.61.144.153

The article was downloaded on 07/09/2011 at 14:35

Please note that terms and conditions apply. 


\title{
Amorphous carbon interlayers for gold on elastomer stretchable conductors
}

\author{
M U Manzoor, C L Tuinea-Bobe, F McKavanagh, C P Byrne, D Dixon, \\ $P$ D Maguire and P Lemoine
}

NIBEC, University of Ulster at Jordanstown, Shore Road, Newtownabbey, Co. Antrim, BT37 0QB, Northern Ireland, UK

E-mail: Manzoor-m@email.ulster.ac.uk

Received 28 January 2011, in final form 22 March 2011

Published 1 June 2011

Online at stacks.iop.org/JPhysD/44/245301

\begin{abstract}
Gold on polydimethylsiloxane (PDMS) stretchable conductors were prepared using a novel approach by interlacing an hydrogenated amorphous carbon $(\mathrm{a}-\mathrm{C}: \mathrm{H})$ layer between the deposited metal layer and the elastomer. AFM analysis of the a-C : $\mathrm{H}$ film surface before gold deposition shows nanoscale buckling, the corresponding increase in specific surface area corresponds to a strain compensation for the first 4-6\% of bi-axial tensile loading. Without this interlayer, the deposited gold films show much smaller and uni-directional ripples as well as more cracks and delaminations. With a-C : $\mathrm{H}$ interlayer, the initial electrical resistivity of the metal film decreases markedly (280-fold decrease to $8 \times 10^{-6} \Omega \mathrm{cm}$ ). This is not due to conduction within the carbon interlayer; both a-C : H/PDMS and PDMS substrates are electrically insulating. Upon cyclic tensile loading, both films become more resistive, but return to their initial state after 20 tensile cycles up to $60 \%$ strain. Profiling experiments using secondary ion mass spectroscopy and $\mathrm{x}$-ray photoelectron spectroscopy indicate that the a-C : H layer intermixes with the PDMS, resulting in a graded layer of decreasing stiffness. We believe that both this graded layer and the surface buckling contribute to the observed improvement in the electrical performance of these stretchable conductors.
\end{abstract}

(Some figures in this article are in colour only in the electronic version)

\section{Introduction}

Traditional electronic components such as semiconductor devices and micro-machines are fabricated on rigid substrates and, therefore have low strain at failure $(<1 \%$ [1]). More recently, flextronics systems have been introduced, where the electronics can take the shape of the object in which they are integrated [2]. These are now available commercially, they are generally based on thermoplastics like polyimide, can only bear strains of a few per cent and hence can flex but not stretch. Truly stretchable electronic circuit has potential biomedical applications in functional stimulation and retinal implants [3] that must undergo a one-time large deformation from flat to spherical, etc. Smart textiles and conformal pressure sensors are other possible applications. One recent example [4,5] of stretchable devices has been demonstrated by adapting existing semiconductor manufacturing technology to complex curvilinear objects using out-of-plane gold/polyamide interconnects.
The more general issue of preparing stretchable conductors has been addressed by using conducting polymers [6], doped elastomers [7], using ultra-thin silicon substrates [8-10] or more simply metal films on elastomeric substrates, like gold on polydimethylsiloxane (PDMS), this last option having shown the best results to date in term of low resistivity ( $\left.\rho=3 \times 10^{-5} \Omega \mathrm{cm}\right)$, fatigue behaviour and stability [11-13]. The main challenges associated with these metal/elastomer systems are the low strain at failure of the metal film and the compressive stresses resulting from post-deposition cooling [14,15]. These thermal stresses are caused by the large difference in thermal expansion between the two materials and can trigger adhesion failure at the film/substrate interface [16], buckling and film delaminations. The films are generally conducting but covered in tri-branched microcracks with lengths of micrometres and less [11]. Hence, at first sight, the observed performance of these systems is surprising. The current understanding, however, is that the compliance of the elastomer and the array of micro-cracks 
in the gold film help minimize strain at crack tips [17] and confer good fatigue resistance upon tensile loading. For uniaxial loading, Poisson stresses also push the gold ligaments together resulting in shorter electrical path lengths and better conduction under strain. In some cases the film cracking was reduced by using pre-deposition stretching [8, 17-19] to give a compressive stress relief. To date, this has only been attempted for uni-axial loading conditions. Moreover, many groups have used photolithography and finite element modelling [20-22] to minimize in-plane strains. Despite these intense efforts, little is known about the metal/elastomer interface, which has been scarcely investigated, to date. In one study [23], the metallic layers are sandwiched between two PDMS substrates and plasma treatment is used successfully to improve the PDMS/PDMS adhesion by making the surface more hydrophilic. This method, however does not directly control the metal/PDMS adhesion, does not deal with the large post-deposition interfacial strains and also does not provide a mechanical fatigue characterization of the conductors. In this paper, a novel approach is presented using thin interlayers of hydrogenated amorphous carbon $(\mathrm{a}-\mathrm{C}: \mathrm{H})$ precisely to improve the metal/elastomeric interface.

\section{Experimental}

\subsection{Materials}

Gold was chosen for its high conductivity, inertness, ductility and non-toxicity and PDMS for its good strechability, processability and biocompatibility [17]. PDMS (Sylgard 184 with $10 \%$ cross-linker agent from Dow Corning) was cast onto PTFE moulds at room temperature for $24 \mathrm{~h}$. This produced tough, uniform, transparent and smooth membranes $\left(R_{\mathrm{a}} \sim 5 \mathrm{~nm}\right.$, for $2 \times 2 \mu \mathrm{m}^{2}$ TAFM image) $)$, approximately $1.3 \mathrm{~mm}$ thick and $8 \times 8 \mathrm{~cm}^{2}$. These specimens were cut into dog bone samples as per ISO 527-2:1996 type SA, $20 \mathrm{~mm}$ tensile gauge length using an appropriate press.

Thin hydrogenated amorphous carbon $(\mathrm{a}-\mathrm{C}: \mathrm{H})$ films were prepared by $(13.56 \mathrm{MHz})$ PECVD (DIAVAC ACM Ltd. Model: RF10S) system in a capacitively coupled radiofrequency chamber using acetylene as a precursor gas, as described previously [24]. From previous studies on the deposition of a-C: $\mathrm{H}$ film on Silicon substrates [25-29], we know that hard and stiff a-C: H film on Si $(H \sim 10-20 \mathrm{GPa}$, $E \sim 100-200 \mathrm{GPa}$ ) can be prepared with self-bias voltages varying from -100 to $-500 \mathrm{~V}$. This study is not designed as a thorough investigation of the self-bias conditions for the preparation of a-C : $\mathrm{H}$ films on PDMS, hence we selected an intermediate value; $-250 \mathrm{~V}$, deemed adequate for the present purpose. The full preparation parameters for deposition onto $\mathrm{Si}$ and PDMS substrates are given below; ultrasonic cleaning in isopropanol followed by argon purging for $180 \mathrm{~s}$ at $2.13 \mathrm{~Pa} \mathrm{Ar}$ pressure, $60 \mathrm{sccm}$ (standard cubic centimetres per second) of Ar flow and $-300 \mathrm{~V}$ self-bias voltage. The a-C : H deposition was carried out for $20 \mathrm{~s}$, with an argon flow of $2.5 \mathrm{sccm}$, an Ar: $\mathrm{C}_{2} \mathrm{H}_{2}$ flow ratio of $1: 2$ and a $-250 \mathrm{~V}$ self-bias voltage.

The metal deposition was carried out with a magnetron sputtering system (Moorfield Minilab S60 A model) using

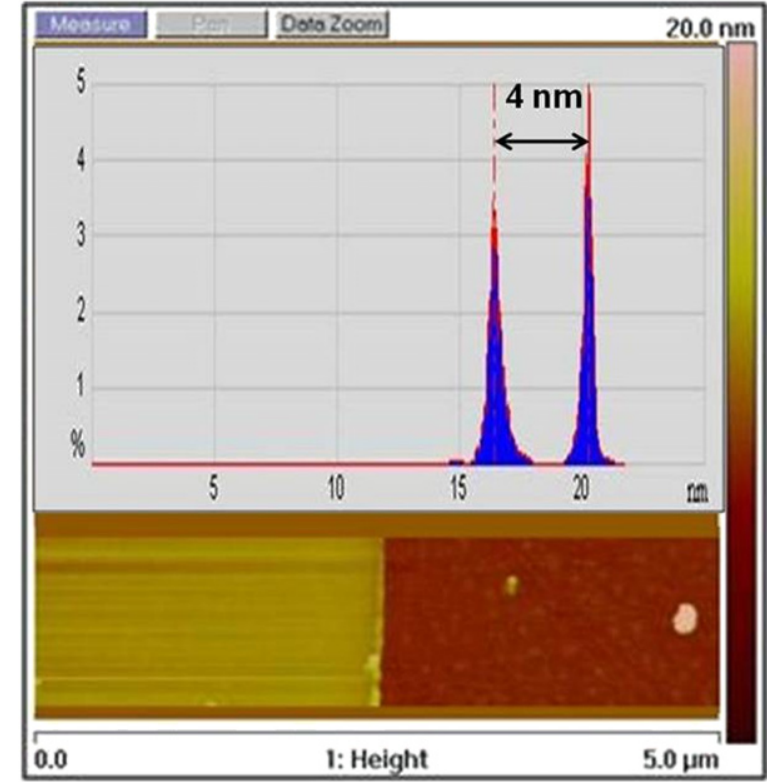

Figure 1. TAFM image of a step height feature for a $10 \mathrm{~s}$ deposition of a-C : $\mathrm{H}$ on a silicon substrate, with the corresponding height histogram

99.99\% purity targets of Ti and Au (Kurt J. Lesker Company, USA). The Ti layer was sputtered for $30 \mathrm{~s}$, at $0.1466 \mathrm{~Pa}$ chamber pressure, $253 \mathrm{~V}$ voltage, 0.26 A current, resulting in a $5 \mathrm{~nm}$ Ti adhesion layer. The gold film was prepared for $60 \mathrm{~s}$ at $0.1466 \mathrm{~Pa}$ chamber pressure, $427 \mathrm{~V}$ voltage and 0.25 A current, resulting in a $25 \mathrm{~nm}$ coated thickness.

\subsection{Characterization}

The PDMS samples and a-C $: \mathrm{H}$ films were analysed by Raman spectroscopy (LabRam 300 with $\mathrm{Ar}^{+} 514 \mathrm{~nm}$ and $\mathrm{HeNe}$, $633 \mathrm{~nm}$ excitation for $20 \mathrm{~s}$ acquisition time). For the a-C-H films, the spectra were fitted using two Gaussian peaks. The results were averaged over five acquisitions at different locations on the films.

DI water contact angle $\theta$ measurements were carried out at room temperature in laboratory atmosphere using a sessile drop system mounted on a goniometric stage (KSV Instruments Ltd. Model: CAM 200 using $5 \mu \mathrm{L} \mathrm{DI}$ water). The reported $\theta$ values represent the average of the left and right hand angles measured from five drops.

Tapping atomic force microscopy (TAFM) images were obtained with a Veeco DI 3200 system using a Si monobeam cantilever $\left(40 \mathrm{~N} \mathrm{~m}^{-1}\right)$ at $1 \mathrm{~Hz}$. The possibility of tip blunting was checked by imaging periodically a standard Nioprobe sample to monitor any eventual change in tip apex geometry. The thickness of the films grown on the Si wafers could be measured using a lift-off technique; pre-deposition the substrates were marked with a resist pen stripe. After deposition, gentle sonication in acetone removed the film region directly above the stripe, leaving a clean step height, as shown in figure 1 .

Scanning electron microscopy (SEM) images were acquired with FEI Quanta 200 3D and Hitachi S3100 systems, both operated with a tungsten (W) filament at accelerating 

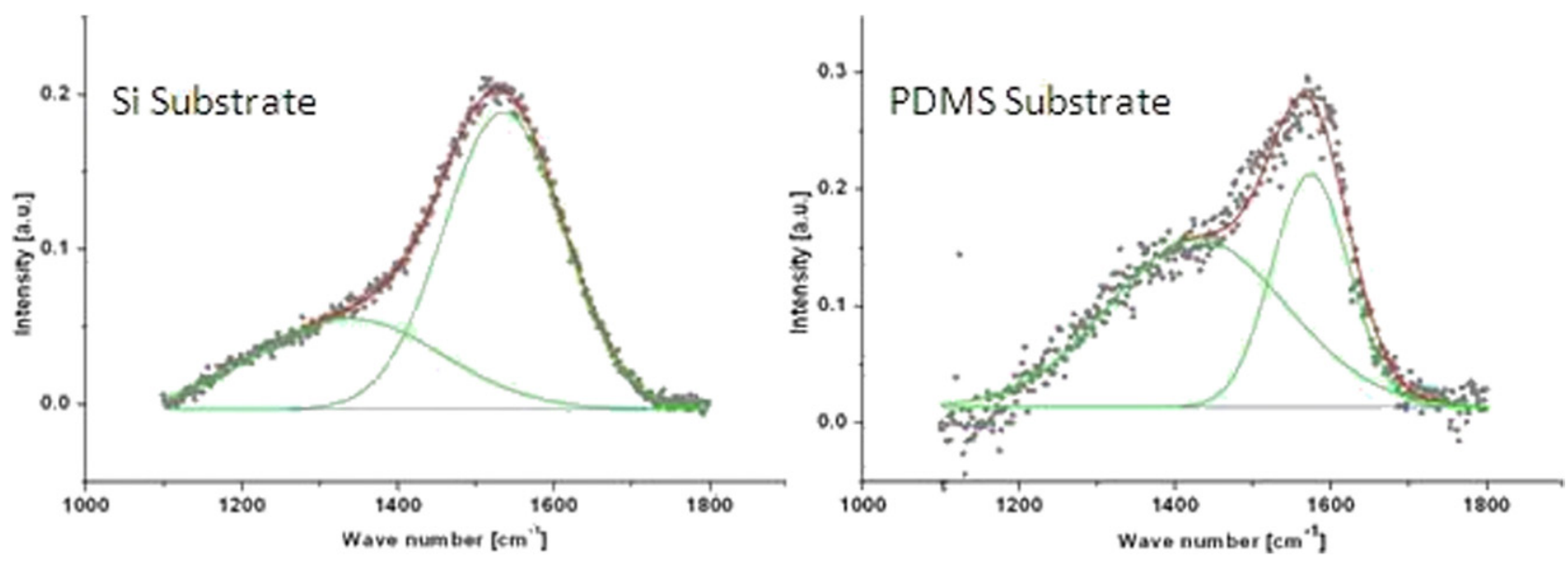

Figure 2. Raman spectra obtained with $514 \mathrm{~nm}$ excitation wavelength for a-C : H film on Si and PDMS substrates.

voltages ranging from 5 to $30 \mathrm{kV}$. The images could be formed with either standard secondary electron or backscattered detections, in high vacuum and low vacuum modes. In all cases the samples were connected to the specimen stage with copper tape.

The electrical and fatigue measurements of the stretchable conductors were performed with an Instron 3344 tensile tester with a $20 \mathrm{~mm}$ gauge length according to ISO 527-2:1996. The PDMS coupons had a tensile modulus of $\sim 1.2 \mathrm{MPa}$ with strain at failure in excess of $100 \%$. The contacts were made of silver wires embedded into a cured silver-epoxy bead (ITW Chemtronics USA), deposited on the shoulder section of the dog bone to make two terminals for electrical measurements, away from the parallel gauge section, then cured for $24 \mathrm{~h}$ at room temperature and connected to the electrical measuring apparatus (Turnbill DC source with current and voltage across sample measured independently). At each contact point, two non-touching silver wires were inserted into the silverepoxy bead to test the continuity and integrity of the silverepoxy contacts. Generally, these measurements gave very low resistance values $(<0.5 \Omega)$ for both samples. Moreover, we do not anticipate significant contact resistance issues between the gold and silver-epoxy layer. Hence we believe that any subsequent difference in electrical behaviour between these two samples is not caused by variation of contact resistance. Moreover, measurements on the a-C:H/PDMS and PDMS surfaces showed that both these substrates are electrically insulating. Indeed, previous measurements in our laboratory have shown that a-C:H layers have resistivity values around $10^{12}-10^{14} \Omega \mathrm{cm}[30]$.

The cycling consisted in a series of 5 slow cycles at $1.5 \mathrm{~mm} \mathrm{~min}^{-1}$ crosshead speeds up to $20 \%$ strain, a series of 10 fast cycles at $3 \mathrm{~mm} \mathrm{~min}^{-1}$ crosshead speed up to $60 \%$ strain and then again 5 slow cycles at $20 \%$ strain. The variations in the electrical resistance upon extension were manually recorded. For this reason, this cycling experiment was only conducted on two sample types, with and without a-C:H interlayers, although other batches were also prepared with the same deposition procedures and subjected to SEM and AFM characterization.

Surface analysis was carried out firstly with a timeof-flight secondary ion mass spectrometer (ToF-SIMS from
ionTof) using a $10 \mathrm{keV} \mathrm{Cs}$ ion source for analysis and a $25 \mathrm{kV}$ Bi ion source for profiling. Spectra were acquired for both positive and negative secondary ions over a mass range of $m / z 0-190$. Secondary ions of a given polarity were extracted and detected using a two-stage reflectron time-offlight mass analyser equipped with a pair of stacked microchannel plates with a time-to-digital converter. The surfaces were also examined with an X-ray photoelectron spectroscopy (XPS) system (Kratos Axis Ultra DLD spectrometer) equipped with a monochromatic AlK $\alpha$ x-ray $(1486.6 \mathrm{eV})$. The chamber pressure was maintained at $<5 \times 10^{-8}$ Torr and surface charging was compensated with a secondary electron gun. Wide energy survey scans (WESS) $(0-1300 \mathrm{eV})$ with step size of $0.5 \mathrm{eV}$ were used to identify all the elements present on the sample, specific spectral region of interest were scanned with $0.05 \mathrm{eV}$ step size.

Depth profiling of a-C :H/Si and a-C :H/PDMS samples were also performed on ToF-SIMS in order to check the depth of graded layer of a-C : $\mathrm{H}$ in PDMS. For sputtering purpose we used $10 \mathrm{keV} \mathrm{Cs}$ ions and $25 \mathrm{keV}$ Bi ions was used for analysis.

\section{Results}

Figure 1 shows an TAFM top view and corresponding height histogram of an ultra-thin film of a-C : $\mathrm{H}$ onto a Si substrate with a $10 \mathrm{~s}$ deposition time. The analysis of the height histogram of this step height edge shows that the film is $\sim 4 \mathrm{~nm}$ thick. For $20 \mathrm{~s}$ deposition time, we obtain a $14 \mathrm{~nm}$ thickness. This would indicate that after the initial stage of deposition the growth rate increases, probably because growth is preceded by a surface modification/implantation stage, as described by many growth models [31].

Figure 2 shows Raman spectra obtained from $514 \mathrm{~nm}$ excitation of a-C:H films deposited onto $\mathrm{Si}$ and PDMS substrates. One recognizes the typical a-C : $\mathrm{H}$ spectral features; a broad asymmetric peak with two components, the main $\mathrm{G}$ peak around $1530 \mathrm{~cm}^{-1}$ representative of the $\mathrm{E} 2 \mathrm{~g}$ mode and a lower frequency shoulder at approximately $1320 \mathrm{~cm}^{-1}$ corresponding to the $\mathrm{A} 1 \mathrm{~g}$ breathing mode of graphite, the latter being only Raman active in disordered regions around graphitic clusters [29], hence called D peak. Comparing the 


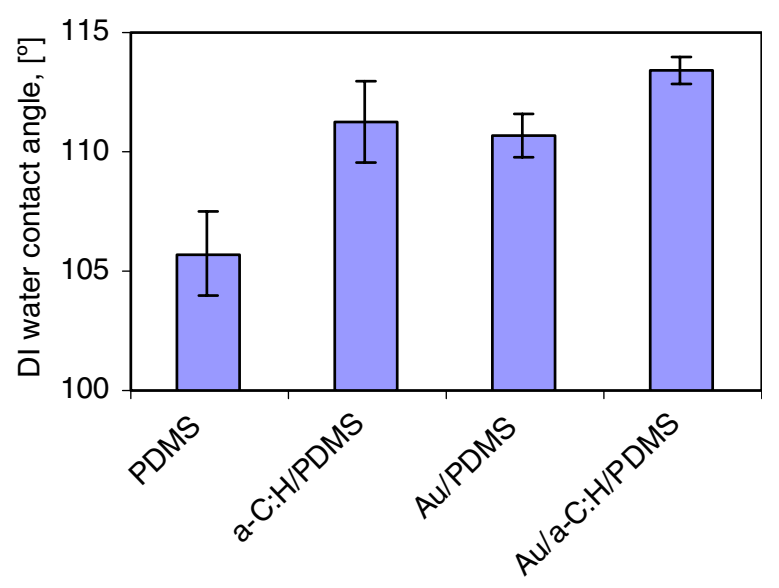

Figure 3. DI water contact angle values for the various surfaces.

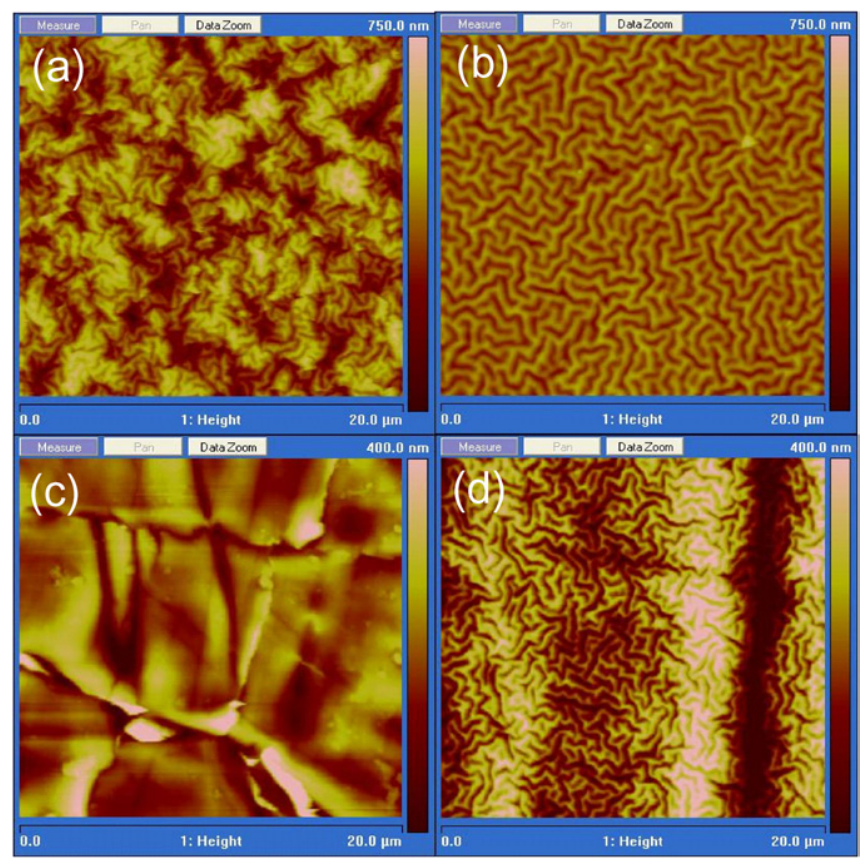

Figure 4. AFM images: (a) a-C : H/PDMS with $20 \mathrm{~s}$ deposition time, (b) a-C:H/PDMS with $60 \mathrm{~s}$ deposition time, (c) Au/PDMS with $20 \mathrm{~s}$ deposition time and $(d) \mathrm{Au} / \mathrm{a}-\mathrm{C}: \mathrm{H} / \mathrm{PDMS}$ with $20 \mathrm{~s}$ deposition time.

films deposited onto the two substrates, we find different $G$ position and $I_{\mathrm{D}} / I_{\mathrm{G}}$ ratios of $1531 \mathrm{~cm}^{-1}$ and 0.27 for $\mathrm{Si}$ and $1533 \mathrm{~cm}^{-1}$ and 0.44 for PDMS. This indicates that the film deposited onto PDMS is more graphitic. The spectra with $633 \mathrm{~nm}$ excitation show approximately similar features for the films grown on $\mathrm{Si}$. However, at $633 \mathrm{~nm}$, there is a significant number of Raman peaks coming from the PDMS functional groups which make the spectral interpretation difficult.

Contact angle results are shown in figure 3, overall, all surfaces are hydrophobic and all film surfaces display larger values than the pristine PDMS surface. Despite this, the differences in $\theta$ values are relatively small, indicative of a similarity in wetting behaviours, possibly implying compatible bonding characteristics.

Figure 4 shows TAFM images of the film surfaces. The a-C : H films on PDMS display rippled surfaces, with the ripple wavelength increasing with film thickness, $552 \pm 20 \mathrm{~nm}$ and $710 \pm 30 \mathrm{~nm}$, respectively, for $20 \mathrm{~s}$ and $60 \mathrm{~s}$ deposition times. This trend is as expected from thin-film buckling theory [9]. The gold film deposited onto this PDMS with a-C : H interlayer (Au/a-C : H/PDMS) shows very similar rippled features, with fewer cracks and delaminations. By contrast, the gold film on PDMS (Au/PDMS) displays only cracks and folds, randomly oriented.

Initially, the samples with and without a-C $: \mathrm{H}$ interlayers have a resistance of $8-10 \Omega$ and $3 \mathrm{k} \Omega$, respectively, hence giving a $280 \times$ decrease in electrical resistance. Upon tensile loading, the resistance of the sample without interlayer does not change markedly, that is it remains in the $\mathrm{k} \Omega$ regime. However, the film with a-C: $\mathrm{H}$ interlayer shows a substantial increase in resistance under loading, again around $2-4 \mathrm{k} \Omega$, but regains its low resistance value at the end of each loading cycle (represented by arrows in figure 5), displaying a final resistance value similar to the original one. Some of these low resistance points are indicated with arrows on figure 5. These results indicate that both samples have resisted fairly well the fatigue experiment but that the film with interlayer is a better stretchable conductor insofar as it has a significantly lower zero-load resistance.

Figures 6-9 show $20 \mathrm{kV}$ secondary electron SEM images of the two samples at various stages of the tensile cycling experiments. These images were obtained in the mid-span section of the dog bones. Before cycling, the two samples show surface morphologies similar to those observed in the TAFM micrographs of figures $4(c)$ and $(d)$. As cycling progresses, more cracks and delaminations appear on both samples. At low strains and cycle numbers, the cracks are mainly perpendicular to the tensile direction, as the damage increases longitudinal cracks due to Poisson stresses also appear. In figure 10, we present a statistical analysis of a series of low magnification SEM micrographs for both these samples before and after cycling. In these cases the images were obtained in low vacuum mode with back-scatter detection to maximize atomic number contrast between the gold film and the PDMS substrate and minimize the influence of charging. Using three different images, we analysed the mean and standard deviations of the following quantities; number of cracks in the image $(n)$, crack length $\left(L_{\mathrm{m}}\right.$ in $\left.\mu \mathrm{m}\right)$ and cumulative crack length (sum of all crack lengths, $L_{\mathrm{T}}$ in $\mu \mathrm{m}$ ) which relates to the crack density. In addition, we also used contrast histograms of these images to estimate the mean and standard deviation of the delamination area (DA in \%). Figure 10 shows that overall, all these damage indicators are lower for the film with an a-C: $\mathrm{H}$ interlayer. This remains the case before and after fatigue. This statistical analysis also indicates that the cycling brought more delaminations on both samples.

The XPS analysis of the samples is presented in figure 11 , for $\mathrm{x}$-ray incidence angles varying from $0^{\circ}$ to $60^{\circ}$, corresponding to approximate XPS sampling depth of $8 \mathrm{~nm}$ to $2 \mathrm{~nm}$, respectively. The angular scan for PDMS shows more or less constant atomic concentrations. For the a-C:H/PDMS system at $10 \mathrm{~s}$ deposition time, there is a gradual increase in $\mathrm{C}$ at\% and decrease in $\mathrm{Si}$ at\%, as the angle increases (i.e. proximity to the surface); i.e. the surface of this film is C-rich 

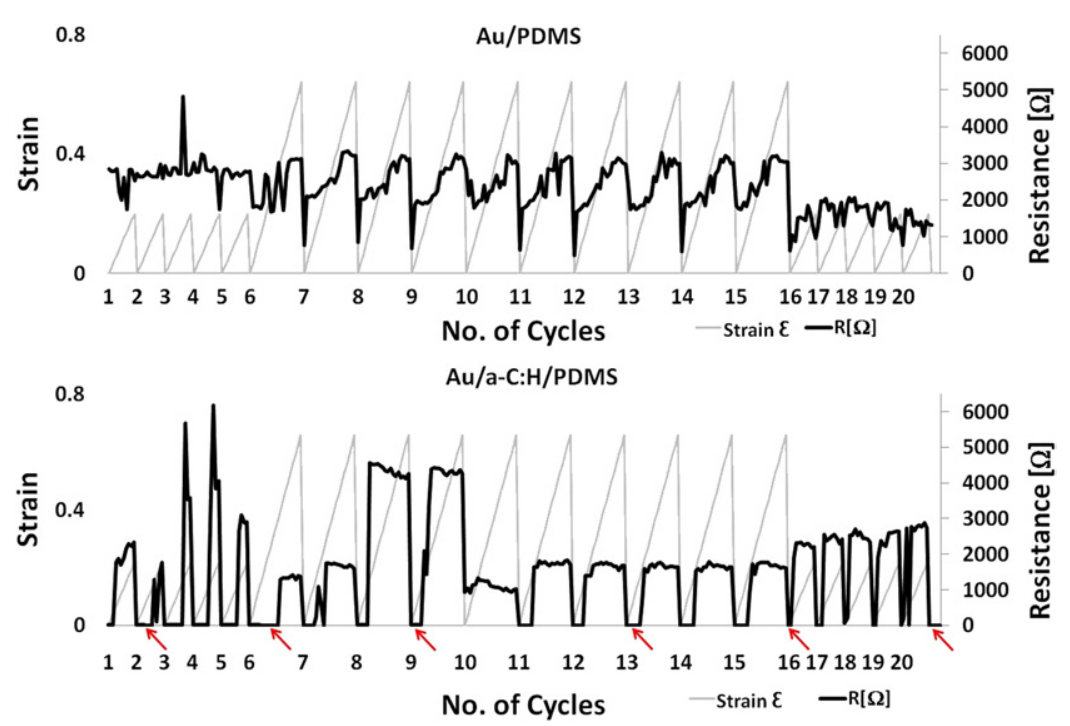

Figure 5. Tensile cycling of the two samples (Au/PDMS and Au/a-C:H/PDMS), the graphs show both the electrical resistance and mechanical strain. (Arrows representing lower resistance values.)
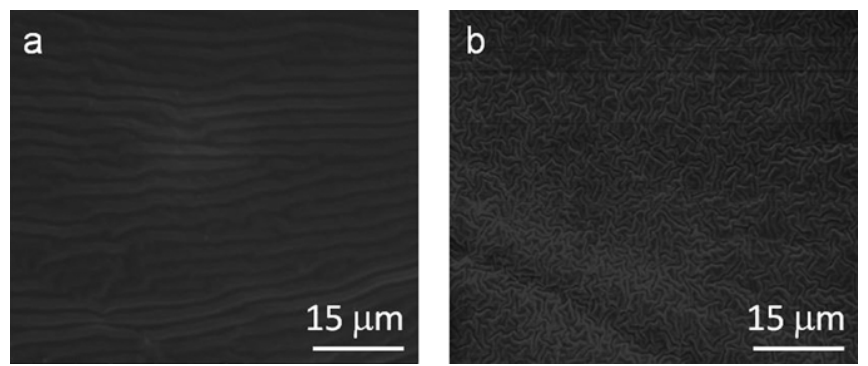

Figure 6. SEM images before fatigue (a) Au/PDMS (b) $\mathrm{Au} / \mathrm{a}-\mathrm{C}: \mathrm{H} / \mathrm{PDMS}$.
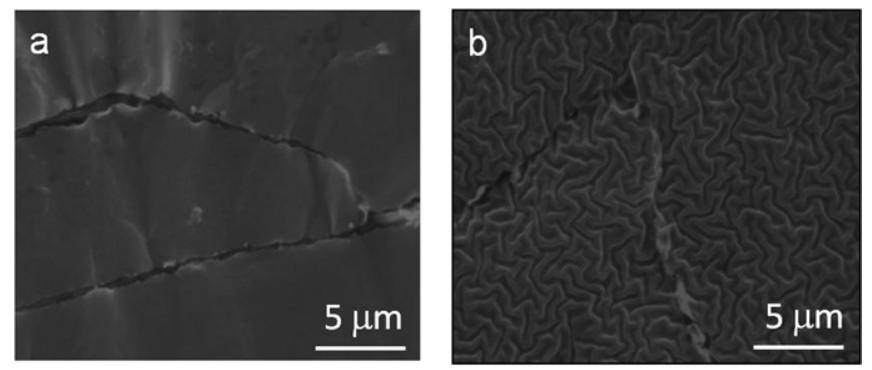

Figure 7. SEM images after the first 5 cycles at $20 \%$ extension. (a) Au/PDMS and (b) Au/a-C:H/PDMS.

and Si-deficient, when compared with the PDMS substrate. The same $10 \mathrm{~s}$ deposition onto a Si substrate gives much sharper trends, larger increase of the $\mathrm{C}$ at $\%$ and decrease of the $\mathrm{O}$ at $\%$ and $\mathrm{Si}$ at $\%$ as the angle increases. This indicates that the a-C : H layer on $\mathrm{Si}$ is probably denser. Looking now at the $20 \mathrm{~s}$ deposition time on PDMS, we find flat profiles for all at $\%$ with $\mathrm{C} \%$ somewhat intermediate between those of the $10 \mathrm{~s}$ a-C $: \mathrm{H} / \mathrm{Si}$ and $10 \mathrm{~s}$ a-C:H/PDMS samples. This indicates that the film thickness is much too large to give profiling information. It also suggests that this film is of intermediate density between that of the $10 \mathrm{~s}$ a-C:H/PDMS and the $10 \mathrm{~s}$ a-C $: \mathrm{H} / \mathrm{Si}$.

The ToF-SIMS data are shown in figure 12. The spectrum of the a-C:H films on Si display an oxygen peak at around
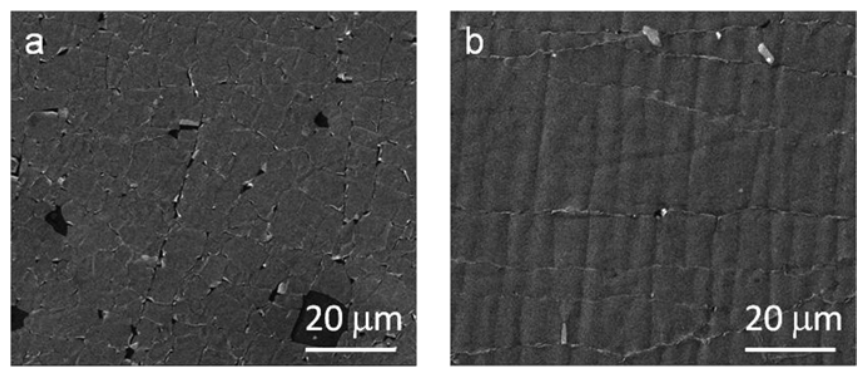

Figure 8. SEM images after first 5 cycles at $10 \%$ extension and then 10 cycles at $60 \%$ extension. (a) Au/PDMS and (b) $\mathrm{Au} / \mathrm{a}-\mathrm{C}: \mathrm{H} / \mathrm{PDMS}$.
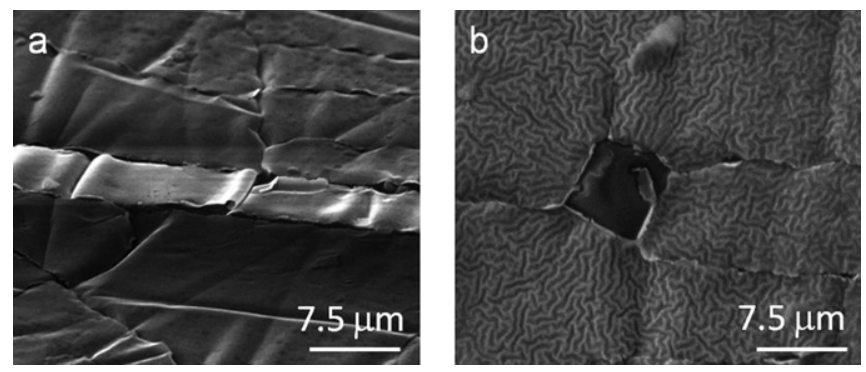

Figure 9. SEM images after 5 cycles at $10 \%$ extension, 10 cycles at $60 \%$ extension and, finally, 5 cycles at $20 \%$ extension. (a) $\mathrm{Au} / \mathrm{PDMS}$ and (b) Au/a-C : H/PDMS.

$300 \mathrm{~s}$ indicative of an $\mathrm{SiO}_{2}$ native oxide layer, not seen for the other substrate. Moreover, for this film on $\mathrm{Si}$, the profiles are sharper and change over smaller sputtering times than for the film deposited onto PDMS. This is again indicative of a significant intermixing of the carbon ions within the polymer matrix, yielding a graded interface.

\section{Discussion}

Most published investigations on a-C:H films on PDMS substrates have studied much thicker carbon films [32, 33]. In 

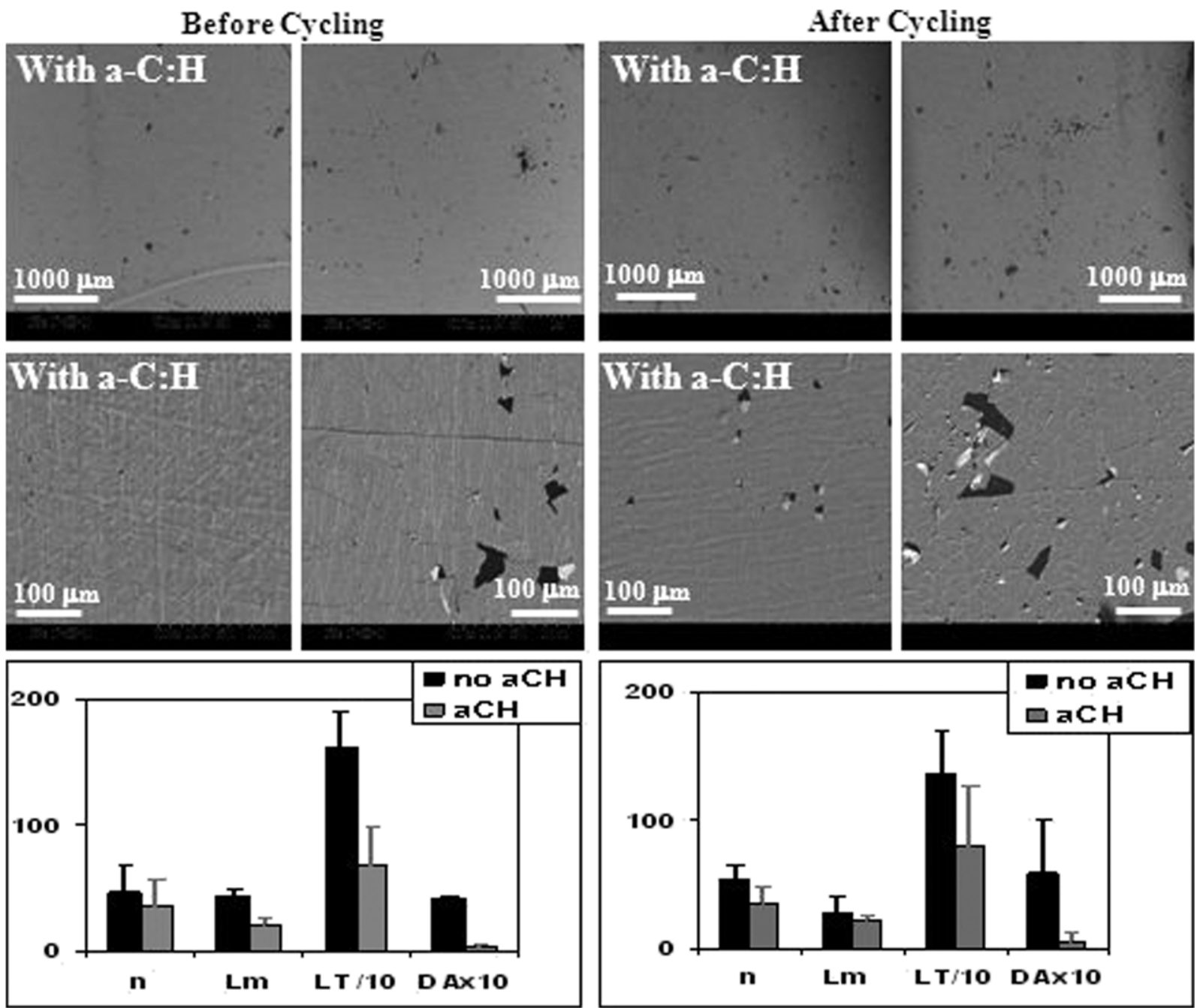

Figure 10. Statistical analysis of low magnification SEM micrographs before and after fatigue for gold films with (labelled) and without (unlabelled) a-C : H interlayers, where $n=$ Total no of cracks, $L_{\mathrm{m}}$-mean crack length $(\mu \mathrm{m}), L_{\mathrm{T}}$ - total crack length $(\mu \mathrm{m})$ and DA-delaminated area $(\%)$.
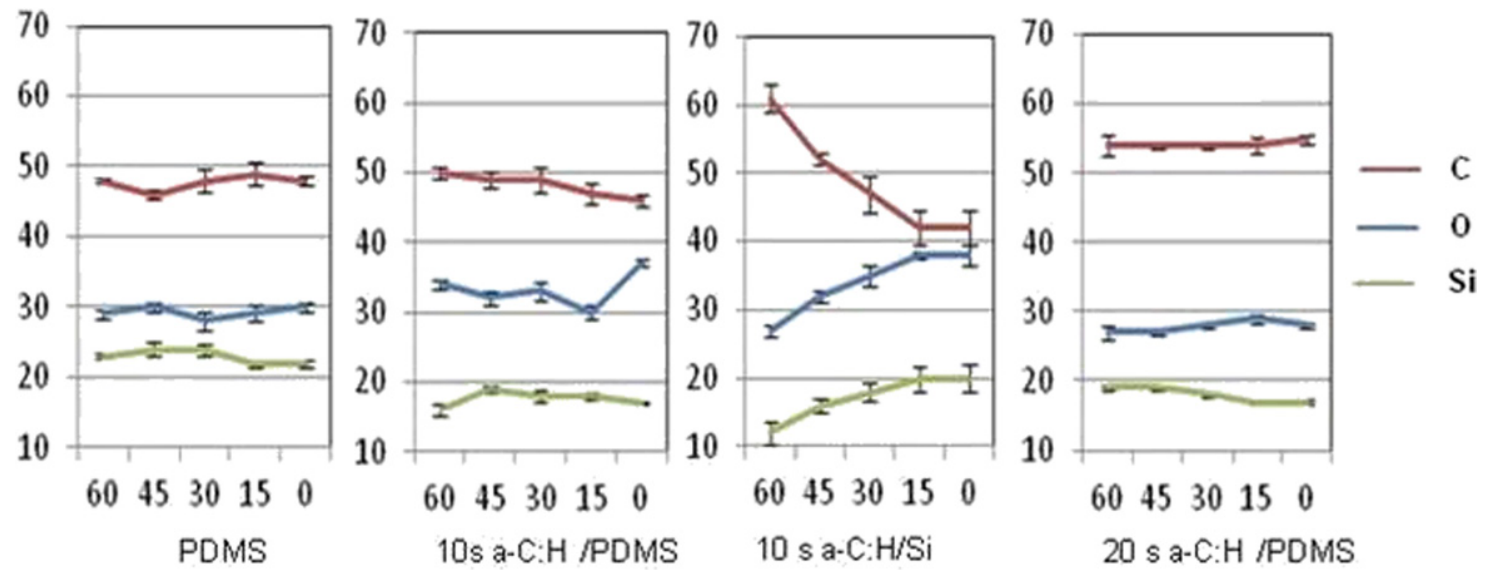

Figure 11. XPS at\% of four samples for various incidence angles, expressed in degrees.

the sub- $20 \mathrm{~nm}$ region, the deposition of a- $\mathrm{C}: \mathrm{H}$ is believed to be strongly influenced by the substrate $[34,35]$, with plasma ions and radicals adsorbing at preferential sites on the substrate, being dehydrogenated at a later stage by the plasma and hence resulting in a continuously evolving, densifying film [36].
It is therefore not surprising that $\mathrm{Si}$ and PDMS substrates should give different carbon films, with more intermixing between the film and substrate for the low density PDMS substrate, as shown in the XPS and SIMS analysis discussed above. Analysis of ion penetration ranges using the SRIM 

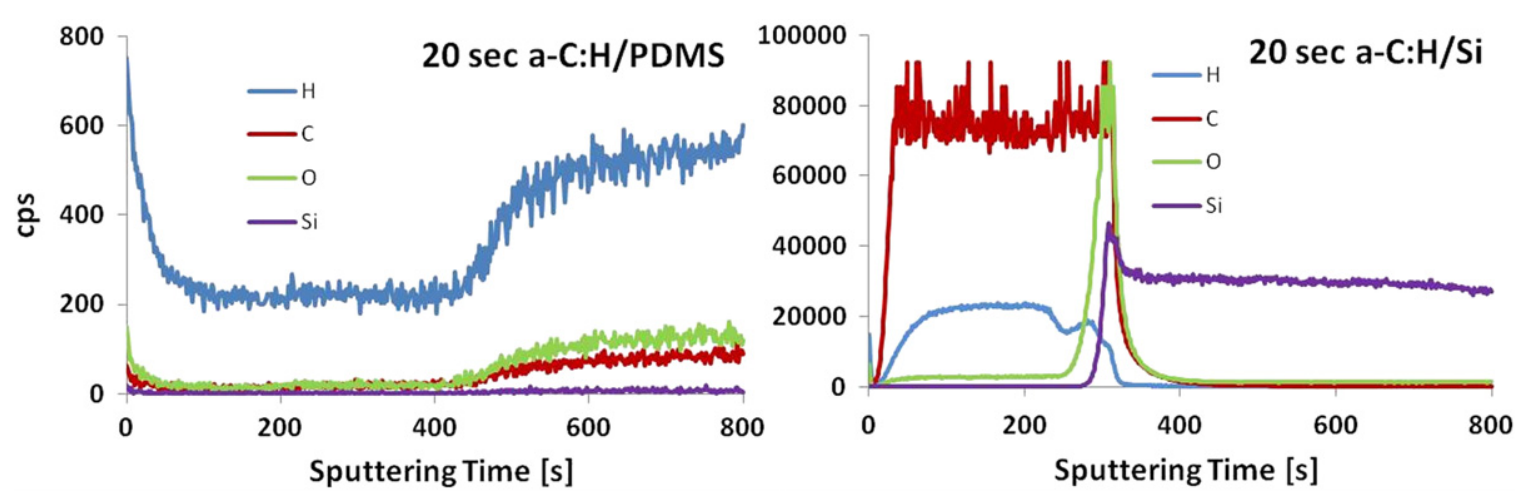

Figure 12. Depth profiling of a-C :H/PDMS and a-C:H/Si.

formalism [37] indicates that the projected range of carbon ions with $250 \mathrm{eV}$ energy (PECVD self-bias voltage of the substrate) is $3.7 \mathrm{~nm}$ in PDMS and $1.4 \mathrm{~nm}$ in Si. The SIMS profile for the $20 \mathrm{~s}$ a-C $: H$ on $\mathrm{Si}$ corresponds to a $14 \mathrm{~nm}$ carbon layer from the surface to the silica native layer ( $\sim 300$ s sputtering time), giving an average sputtering rate for a-C: $\mathrm{H}$ of $0.047 \mathrm{~nm} \mathrm{~s}^{-1}$. Using this value for the $20 \mathrm{~s}$ a-C :H/PDMS, we find that this layer is approximately $21 \mathrm{~nm}$ thick with a graded interface region of $\sim 100 \mathrm{~s}(4.7 \mathrm{~nm})$, a value commensurate with the $3.7 \mathrm{~nm}$ calculated by SRIM. Unfortunately, measuring the thickness of an ultra-thin a-C : $\mathrm{H}$ film on a very compliant polymeric substrate such as PDMS ( $E \sim 1.2 \mathrm{MPa}$ ) is challenging; the substrate deforms, even for gentle TAFM conditions and the wrinkle pattern prevent meaningful XRR or ellipsometric analysis.

The buckling observed in the AFM images of figure 4 is typical of stiff films on compliant substrates, the issue having been discussed extensively in the case of metal films on elastomeric substrates $[9,38]$. The large thermal expansion coefficient of the substrate means that thermal stresses on cooling from the deposition temperature to room temperature result in a compressed film which may buckle spontaneously. The relevant theoretical descriptions are well established $[9,15]$ and allow the definition of the critical buckling stress and the ripple wavelength and amplitude as a function of the stiff layer thickness and Young's moduli of the stiff layer and elastomeric substrate. For the case of the $20 \mathrm{~s}$ a-C :H/PDMS film $(\lambda=550 \mathrm{~nm})$, this formalism would give an $E$ value of $0.3-1 \mathrm{GPa}$. Generally, Young's modulus of a-C : H films is much higher, for instance even polymer-like carbon films have $E$ value of $\sim 15-20 \mathrm{GPa}$ [39]. Hence, this buckling could not be due solely to thermal stress on cooling. Indeed, the modelling of buckling for diamond-like carbon (DLC) is more complicated as compression also results from ionic sub-plantation during growth [31]. This also occurs for room temperature growth. In some cases, both effects are considered $[40,41]$, but only to study the possible delamination of thin DLC films from rigid substrates, not applicable to the present study.

With regard to the formed stretchable conductors, figure 4 indicates that the buckling pattern observed on the carbon interlayer is transferred to the gold film. Analysing the specific surface area, we found that these compressed, rippled surfaces correspond to a substantial bi-axial strain, $4-6 \%$ for the a-C : $\mathrm{H}$ and $\mathrm{Au} / \mathrm{a}-\mathrm{C}: \mathrm{H}$ layers compared with only $\sim 1 \%$ for the $\mathrm{Au}$ layer deposited directly onto PDMS. These ripples would therefore protect the film against the first stages of bi-axial tensile loading.

The electrical measurements show that the gold films with carbon interlayer have a much smaller resistance (280 times smaller) than those without interlayer. This result is consistent with the statistical analysis of figure 10; the total crack length (LT) and delaminated areas (DA) are much smaller for the film with carbon interlayer. It is well known, from other studies of gold films on PDMS, that it is precisely this array of microcracks which limits conduction in gold films on elastomeric substrates [42]. Taking into account the dimension of the gold strip (20 mm length, combined $(\mathrm{Au}+\mathrm{Ti})$ thickness $=30 \mathrm{~nm}$, width $=5.5 \mathrm{~mm}$ ), the $8-10 \Omega$ value for the sample with carbon interlayer corresponds to a film resistivity value of $8 \times 10^{-6} \Omega \mathrm{cm}$. This resistivity value is obviously larger than that of bulk gold $\left(\sim 2.4 \times 10^{-6} \Omega \mathrm{cm}\right)$, as the film is cracked, but smaller than the best published values to date $\left(\sim 3 \times 10^{-5} \Omega \mathrm{cm}[42]\right)$. This is an encouraging result which we believe is caused by two attributes of the a-C:H layer, its large specific surface area and the graded nature of this layer which may further reduce interfacial stresses.

This study also gave the puzzling result that the Au/PDMS film conducted better after tensile cycling $(\sim 1400 \Omega)$ than before $(\sim 3000 \Omega)$. A similar trend has been previously reported in another tensile cycling investigation of the Au/PDMS system [42], giving initial resistance of 40-200 $\Omega$ seemingly decreasing to $30-80 \Omega$ after 1000 cycles, although this is not commented on by the authors. These authors nevertheless discuss the film microstructure evolving from a random micro-crack distribution to a stable network of metal islands. In the process, the crack edges rubbing against each other become smoother, as gold is a relatively soft and ductile metal. Moreover, as the film is under compression, this smoothing process could yield to better contacts between gold ligaments, resulting in the observed effect. Figures 4(c) and 7 indicate that, in its pristine form, the percolation between gold ligaments occur at discrete contact points, defined by the jagged edges of the crack boundaries. Again, smother edges would result in better contacts and improved conduction. For the Au/a-C:H/PDMS sample, the crack density is half that observed in the Au/PDMS system (see figure 10) and therefore conduction depends less crucially on these contact points. 
These are encouraging results as the materials produced have excellent electrical properties and may be advantageous for continuous monitoring in smart fabric applications where high stretch events may occur. For instance, when a user is fitting the garment, the stresses could be high, whereas while wearing the garments, when the device is operated, the stresses are usually low.

However, these are only initial results and more can be done to further improve the interface of gold/PDMS conductors. For instance, this strategy of forming a wrinkled interface would also work for more brittle interlayer materials, as it is the cracks in the metal film which matters, not those in the interlayer; this giving potentially a wide range of interlayers with, possibly larger specific surface area or better adhesion. This could, lead to better conductors showing improved electrical properties on loading.

\section{Conclusion}

In this paper, we demonstrated that ultra-thin a-C:H interlayers improve the electrical characteristics of gold films sputtered onto PDMS substrates. This interlayer resulted in a wrinkled bi-axial random pattern which increased the specific surface area of the metal film. SEM micrographs and electrical measurements show that the prepared gold films on PDMS resisted tensile cycling experiments, with the specimen with carbon interlayer displaying improve electrical performance. SIMS and XPS profiling indicate that the a-C : $\mathrm{H}$ layer intermixes with the PDMS substrate, the resulting graded interface probably contributing to reduce interfacial stresses and the observed reduction of cracking in the film. These preliminary results pave the way for further improvements in stretchable conductors based on metal films deposited on elastomer substrates.

\section{Acknowledgments}

The main Author (MUM) would like to acknowledge the Vice Chancellor's Research Scholarship, University of Ulster for providing the funds to carry out all the research work. Dr Derk Rading, from ION-TOF Technologies GmbH is also greatly acknowledged for helpful discussions regarding SIMS spectroscopy.

\section{References}

[1] Huang H and Spaepen F 2000 Tensile testing of free-standing $\mathrm{Cu}, \mathrm{Ag}$ and $\mathrm{Al}$ thin films and $\mathrm{Ag} / \mathrm{Cu}$ multilayers Acta Mater. 483261

[2] Gonzalez M, Axisa F, Bulcke M V, Brosteaux D, Vandevelde B and Vanfleteren J 2008 Design of metal interconnects for stretchable electronic circuits Microelectron. Reliab. 48825

[3] Hsu P, Bhattacharya R, Gleskova H, Huang M, Xi Z, Suo Z, Wagner S and Sturm J C 2002 Thin-film transistor circuits on large-area spherical surfaces Appl. Phys. Lett. 811723

[4] Ko H C et al 2009 Curvilinear electronics formed using silicon membrane circuits and elastomeric transfer elements Small 52703

[5] Ko H C et al 2008 A hemispherical electronic eye camera based on compressible silicon optoelectronics Nature 454748
[6] Brady S, Diamond D and Lau K T 2005 Inherently conducting polymer modified polyurethane smart foam for pressure sensing Sensors Actuators A 119398

[7] Shiga T, Okada A and Kurauchi T 1993 Electroviscoelastic effect of polymer blends consisting of silicone elastomer and semiconducting polymer particles Macromolecules 266958

[8] Sun Y, Choi W M, Jiang H, Huang Y Y and Rogers J A 2006 Controlled buckling of semiconductor nanoribbons for stretchable electronics Nature Nanotechnol. 1201

[9] Khang D Y, Rogers J A and Lee H H 2009 Mechanical buckling: mechanics, metrology, and stretchable electronics Adv. Funct. Mater. 191526

[10] Xiao J, Carlson A, Liu Z, Huang Y, Jiang H and Rogers J 2008 Stretchable and compressible thin films of stiff materials on compliant wavy substrates Appl. Phys. Lett. 93013109

[11] Lacour S P, Chan D, Wagner S, Li T and Suo Z 2006 Mechanisms of reversible strechability of thin metal films on elastomeric substrates Appl. Phys. Lett. 88204103

[12] Lacour S P, Wagner S, Huang Z and Suo Z 2003 Stretchable gold conductors on elastomeric substrates Appl. Phys. Lett. 822404

[13] Lacour S P, Jones J, Wagner S, Li T and Suo Z 2005 Stretchable interconnects for elastic electronic surfaces Proc. IEEE 931459

[14] Bodö P and Sundgren J E 1986 Titanium deposition onto ion-bombarded and plasma-treated polydimethylsiloxane surface modification, interface and adhesion Thin Solid Films 136147

[15] Bowden N, Brittain S, Evans A G, Hutchinson J W and Whitesides G M 1998 Spontaneous formation of ordered structures in thin films of metals supported on an elastomeric polymer Nature 393146

[16] Gioia G and Ortiz M 1997 Delamination of compressed thin films Adv. Appl. Mech. 33119

[17] Wagner S, Lacour S P, Jones J, Hsu P H I, Sturm J C, Li T and Suo Z 2004 Electronic skin: architecture and components Phys. E: Low-dimensional Syst. Nanostruct. 25326

[18] Lacour S P, Wagner S, Narayan R J, Li T and Suo Z 2009 Stiff subcircuit islands of diamondlike carbon for stretchable electronics J. Appl. Phys. 100014913

[19] Watanabe M, Shirai H and Hirai T 2002 Wrinkled polypyrrole electrode for electroactive polymer actuators J. Appl. Phys. 924631

[20] Gray D S, Tien J and Chen C S 2004 High-conductivity elastomeric electronics Adv. Mater. 16393

[21] Pelrine R, Kornbluh R, Joseph J, Heydt R, Pei Q and Chiba S 2000 High-field deformation of elastomeric dielectrics for actuators Mater. Sci. Eng. C 1189

[22] Brosteaux D, Axisa F, Gonzalez M and Vanfleteren J 2007 Design and fabrication of elastic interconnections for stretchable electronic circuits IEEE Electron Device Lett. 28552

[23] Morent R et al 2007 Adhesion enhancement by a dielectric barrier discharge of PDMS used for flexible and stretchable electronics J. Phys. D: Appl. Phys. 407392

[24] Lemoine P, Zhao J, Quinn J P, McLaughlin J A and Maguire P 2000 Hardness measurements at shallow depths on ultra-thin amorphous carbon films deposited onto silicon and $\mathrm{Al}_{2} \mathrm{O}_{3}-\mathrm{TiC}$ substrates Thin Solid Films 379166

[25] Lemoine $\mathrm{P}$ et al 2000 Nanoindentation and scratch resistance testing on magnetic tape heads coated with ultra-thin amorphous carbon layers Wear 24479

[26] Zhao J, Lemoine P, Liu Z, Quinn J, Maguire P and McLaughlin J A 2001 A study of microstructure and nanomechanical properties of silicon incorporated DLC films deposited on silicon substrates Diamond Relat. Mater. 101070 
[27] Papakonstantinou P, Zhao J, Lemoine P, McAdams E and McLaughlin J A 2002 The effects of Si incorporation on the electrochemical and nanomechanical properties of DLC thin films Diamond Relat. Mater. 111074

[28] Quinn J, Lemoine P, Maguire P and McLaughlin J A 2004 Ultra-thin tetrahedral amorphous carbon films with strong adhesion, as measured by nanoscratch testing Diamond Relat. Mater. 131385

[29] Lemoine P, Quinn J P, Maguire P and McLaughlin J A 2004 Comparing hardness and wear data for tetrahedral amorphous carbon and hydrogenated amorphous carbon thin films Wear 257509

[30] Maguire P, Magill D, Ogwu A and McLaughlin J A 2001 The insulating properties of a-C: $\mathrm{H}$ on silicon and metal substrates Diamond Relat. Mater. 10216

[31] Robertson J 1993 Deposition mechanisms for promoting $\mathrm{sp}^{3}$ bonding in diamond-like carbon Diamond Relat. Mater. 2984

[32] Kiuru M and Alakoski E 2004 Low sliding angles in hydrophobic and oleophobic coatings prepared with plasma discharge method Mater. Lett. 582213

[33] Tsubone D, Hasebe T, Kamijo A and Hotta A 2007 Fracture mechanics of diamond-like carbon (DLC) films coated on flexible polymer substrates Surf. Coat. Technol. 2016423

[34] Ahmad I, Maguire P, Lemoine P, Roy S S and McLaughlin J A 2004 Deposition of carbon films onto metal and silicon substrates by filtered cathodic vacuum arc, plasma enhanced CVD and unbalanced magnetron sputtering Diamond Relat. Mater. 131346

[35] Ahmad I, Roy S S, Rahman M A, Okpalugo T I T, Maguire P D and McLaughlin J A 2009 Substrate effects on the microstructure of hydrogenated amorphous carbon films Curr. Appl. Phys. 9937

[36] Jacob W 1998 Surface reactions during growth and erosion of hydrocarbon films Thin Solid Films 3261

[37] Ziegler J F, Biersack J and Littmark U 1985 The Stopping and Range of Ions in Solids ed F James et al (New York: Pergamon) vol 1

[38] Jiang H, Khang D, Fei H, Kim H, Huang Y, Xiao J and Rogers J A 2008 Finite width effect of thin-films buckling on compliant substrate: experimental and theoretical studies J. Mech. Phys. Solids $\mathbf{5 6} 2585$

[39] Cho S O and Jun H Y 2005 Surface hardening of poly (methyl methacrylate) by electron irradiation Nucl. Instrum. Methods Phys. Res. B 237525

[40] Bulir J, Jelinek M, Vorlicek V, Chvostova D and Soukup L 1995 Influence of deposition parameters on laser ablation deposited amorphous carbon J. Non Cryst. Solids 188118

[41] Iyer S B, Harshavardhan K and Kumar V 1995 Buckling patterns in diamond-like carbon films Thin Solid Films 25694

[42] Graz I M, Cotton D P J and Lacour S P 2009 Extended cyclic uniaxial loading of stretchable gold thin-films on elastomeric substrates Appl. Phys. Lett. 94071902 